Received: June 25, 2017

\title{
An Improved Performance Evaluation Index System and Fuzzy Evaluation Model of College Students' Ideological and Political Education
}

\author{
Zhiguo $\mathrm{Wu}^{1}$ \\ Xinyang Normal University
}

\begin{abstract}
As the key to ensure the quality of higher education, the ideological and political education of college students is of great significance to improving the comprehensive quality and competitiveness of top talents so that they can better service the society and promote social development. Through analysis of the problems in the performance evaluation of college students' ideological and political education, this paper unveils an improved performance evaluation index system and fuzzy evaluation model. Firstly, the author discusses the perspective of constructing the evaluation index system, and outlines the perspective of constructing the performance evaluation index system of ideological and political education; secondly, the author selects evaluation indices by analyzing the principle of index selection, and constructs a hierarchal performance evaluation index system of college students' ideological and political education on the basis of the selected indices; thirdly, based on the theory of fuzzy mathematics, the author establishes a fuzzy evaluation model of college students' ideological and political education which gives full consideration to the evaluation indices, realizing the quantitative analysis of the performance of college students' ideological and political education; finally, the author summarizes the features and looks at the prospects of the evaluation index system and the evaluation model.
\end{abstract}

\section{Keywords}

Colleges; Ideological and Political Education • Performance Analysis • Evaluation Index System • Fuzzy Evaluation Model

\footnotetext{
${ }^{1}$ Correspondence to: Zhiguo Wu (MA), Xinyang Normal University, Xinyang 464000, China. Email: 1005076958@qq.com 
With the rapid social development, the ideological and political performance of top talents is playing an increasingly important role in promoting high-level scientific and technological innovation and social advancement. Therefore, more and more importance is being attached to the ideological and political education of college students. Scholars have carried out research and analysis from multiple angles, presenting many valuable findings (Zhang, 2011; She, 2014; Wu \& Zhang, 2014; Li, 2012). As the key to ideological and political education, the ideological and political education performance evaluation of college students charts the course for the models, means and methods of implementing college students' ideological and political education in the future, and improves the level of ideological and political education of college students so that these top talents can adapt to social development and serve the society in a better way (Zhang \& Liu, 2012; Long, 2013). So far, there has been some research on the performance evaluation of college students' ideological and political education. Achieving fruitful results in the aspects of evaluation systems, strategies and models, the previous research has played a positive role in promoting the ideological and political education of college students. (Guo \& Li, 2008; Li, 2008; Yang \& Wang, 2010; Li \& Ou, 2015). However, due to the complexity of performance evaluation, especially the limitations of existing evaluation systems and models emerging with the rapid social development, this paper probes into the a brand new performance evaluation system of college students' ideological and political education, and constructs a corresponding performance evaluation model on the basis of fuzzy mathematics (Chatterjee, Mukherjee \& Kar, 2014; Shidpour, Da Cunha \& Bernard, 2016; Ban \& Coroianu, 2015).

\section{A New Perspective of Performance Evaluation of College Students' Ideological and Political Education}

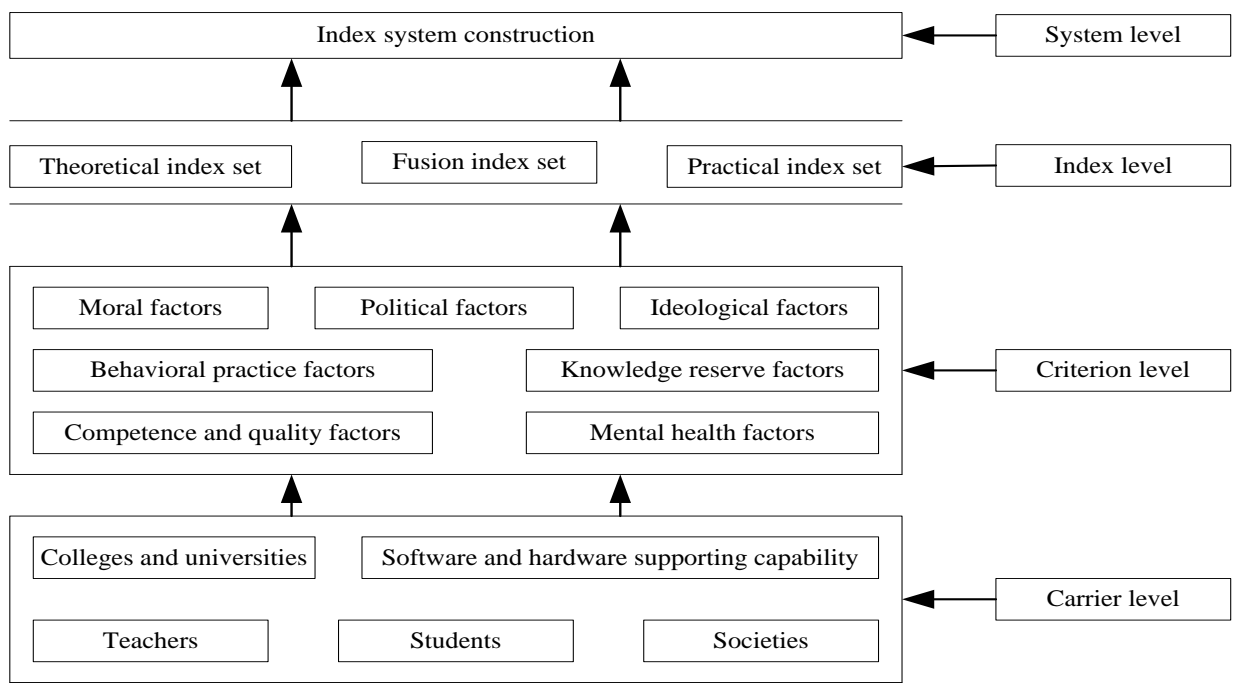

Figure 1. A new perspective of constructing a performance evaluation system of ideological and political education 
Previous performance evaluation systems of college students' ideological and political education are often constructed to analyze issues from a single perspective or at a single level. These systems may have some positive effects on the level of ideological and political education. However, their perspectives are too narrow to have a holistic and integrated view of the problems and find a solution to the problems. Lacking completeness and consistency, these evaluation systems can only be applied within limited areas. Ideological and political performance evaluation index system should be constructed in consideration of the theoretical soundness, practical feasibility, and the interaction between the two indices. Besides, it should be noted that these indices are affected by factors like politics, ideology, knowledge reserve, capacity and quality, moral character, mental health, and behavior, and these factors are closely bounded up with a variety of carriers, such as colleges, the society, teachers, students, software, hardware, etc. To make the results of performance evaluation more scientific, objective and accurate, the performance evaluation systems of college students' ideological and political education should be established from a holistic and integrated perspective. To this end, this paper, through comprehensive analysis and reference to the existing research results, provides a new perspective of constructing a performance evaluation system of college students' ideological and political education. See Figure 1.

\section{Performance Evaluation Index System of College Students' Ideological and Political}

\section{Education}

\section{Principles of index selection}

The performance evaluation indices of college students' ideological and political education should be selected in the following principles:

(1) The principle of scientificity: To ensure the scientific nature of the evaluation, the evaluation indices should be selected properly, rationally in accordance with scientific laws.

(2) The principle of objectivity: To ensure the objectivity and authenticity of the evaluation results, the evaluation indices should be selected in view of the reality and in exclusion of subjective factors.

(3) The principle of hierarchy: Since single-level evaluation indices often fail to clearly describe the evaluation contents of complex problems, thus affecting the effectiveness of the evaluation results, the evaluation indices should be rendered into a hierarchical structure to improve the credibility of the evaluation results.

(4) The principle of relevance: To effectively improve the accuracy of the evaluation results, the evaluation indices should be selected in consideration of the relevance and integration between difference sets of evaluation indices, achieving a clear, modular representation of the relationship.

(5)The principle of integrity and completeness: To make the evaluation results more authentic, the evaluation indices should be selected from the overall perspective. The indices should be consistent, and capable of reflecting the different levels and sides of the overall situation. 
Zhao / An Improved Performance Evaluation Index System and Fuzzy Evaluation Model of College Students' Ideological...

(6) The principle of operability: To improve the reliability of the evaluation results, the evaluation indices should be selected with the aim to quantify the evaluation results.

\section{Construction of evaluation index system}

Table 1

Performance Evaluation Index System of College Students' Ideological and Political Education

\begin{tabular}{|c|c|c|}
\hline Primary Indices & Secondary Indices & Tertiary Indices \\
\hline \multirow{15}{*}{ Theoretical Soundness } & \multirow{5}{*}{ Curriculum Setting } & Plan Rationality \\
\hline & & Curriculum Systematicness \\
\hline & & Contemporariness \\
\hline & & Scientific Development \\
\hline & & Clarity of Purpose \\
\hline & \multirow{6}{*}{$\begin{array}{l}\text { Demonstration by Teaching } \\
\text { Process }\end{array}$} & Teaching Measures \\
\hline & & Teaching Methods \\
\hline & & Teaching Ways and Means \\
\hline & & Teaching Ability \\
\hline & & Teaching Quality and Attitude \\
\hline & & Teaching Contents \\
\hline & \multirow{4}{*}{ Teaching Effect } & Social Satisfaction \\
\hline & & Overall Quality Improvement \\
\hline & & Student Satisfaction \\
\hline & & Actual Progress Against the Plan \\
\hline \multirow{14}{*}{ Practical Feasibility } & \multirow{4}{*}{$\begin{array}{l}\text { Planning of Practical } \\
\text { Activities }\end{array}$} & Rationality \\
\hline & & Scientificity \\
\hline & & Contemporariness \\
\hline & & Expansibility \\
\hline & \multirow{6}{*}{$\begin{array}{l}\text { Implementation of Practical } \\
\text { Activities }\end{array}$} & Appraisal Mode \\
\hline & & Practical Teaching Contents \\
\hline & & Practice Approaches \\
\hline & & Practice Contents and System \\
\hline & & Practice Management Mechanism \\
\hline & & System of Practice Methods \\
\hline & \multirow{4}{*}{ Effect of Practical Mode } & Practice Quality Improvement \\
\hline & & Practice Ability Improvement \\
\hline & & Practical Innovation Ability \\
\hline & & Social Service Capacity \\
\hline \multirow{25}{*}{ Integration Capacity } & \multirow{4}{*}{$\begin{array}{l}\text { Integration of Implementation } \\
\text { Processes }\end{array}$} & Scientificity and rationality of Institutional Settings \\
\hline & & Institutional Perfection and Development \\
\hline & & Staffing \\
\hline & & Mission Planning \\
\hline & \multirow{4}{*}{ Platform Construction } & Unity of Theory and Practice \\
\hline & & Construction and Improvement of Excellent Courses \\
\hline & & Quality of Supporting Software and Hardware \\
\hline & & Social Services \\
\hline & \multirow{4}{*}{$\begin{array}{l}\text { Integration of Plan } \\
\text { Implementations }\end{array}$} & Systematicness \\
\hline & & Innovation \\
\hline & & Effectiveness \\
\hline & & Scientificity \\
\hline & \multirow{5}{*}{ Integration of Carriers } & Consistency \\
\hline & & Adaptability \\
\hline & & Rationality \\
\hline & & Soft and Hard Power Integration \\
\hline & & Internal and External Environment Integration \\
\hline & \multirow{8}{*}{ Integration Results } & Demonstration by Scientific Research Results \\
\hline & & Demonstration by Educational Reform Results \\
\hline & & Rate of Outstanding Talents \\
\hline & & Ideological Improvement \\
\hline & & Political Consciousness Improvement \\
\hline & & Morality Improvement \\
\hline & & Mental Health \\
\hline & & Practicality \\
\hline
\end{tabular}




\section{Selection of evaluation indices}

The performance evaluation indices of ideological and political education are selected from three perspectives, namely the theoretical soundness of ideological and political education, the practical feasibility of ideological and political education, and the integration capacity of ideological and political education.

The theoretical soundness of ideological and political education mainly focuses on theory teaching, including curriculum setting, demonstration by teaching process, and the teaching effect.

The practical feasibility of ideological and political education mainly focuses on practical teaching, including the planning and implementation of practical activities, and the effect of the practice mode.

The integration capacity of ideological and political education mainly focuses on the interaction between the theoretical soundness and practical feasibility, including the integration of institutional and systematic sophistication, platform construction and execution, the integration of plan implementations, the integration of carriers, and demonstration by integration results.

The author further refines the above performance evaluation indices and establishes an improved, hierarchal performance evaluation index system of college students' ideological and political education. See Table 1 for specific contents and hierarchies.

\section{Fuzzy Evaluation Model of College Students' Ideological and Political Education}

Because of the fuzziness of the performance evaluation indices of college students' ideological and political education, this paper uses the triangular fuzzy numbers to build a model for the performance evaluation of college students' ideological and political education (Molinari, 2016; Chandra \& Aggarwal, 2015; Liao \& Chen, 2015).

\section{The concept of triangular fuzzy numbers}

If $b=\left(b^{1}, b^{2}, b^{3}\right)$, and $\left.0 \leq b^{1} \leq b^{2} \leq b^{3}\right), b=\left(b^{1}, b^{2}, b^{3}\right)$ is called a triangular fuzzy number, abbreviated as. Its corresponding fuzzy membership function $\theta_{b}(x)$ is expressed as:

$$
\theta_{b}(x)=\left\{\begin{array}{c}
0, x \leq b^{1} \\
\frac{x-b^{1}}{b^{2}-b^{1}}, b^{1} \leq x \leq b^{2} \\
\frac{b^{3}-x}{b^{3}-b^{2}}, b^{2} \leq x \leq b^{3} \\
0, x \geq b^{3}
\end{array}\right.
$$

If there are two triangular fuzzy numbers $\tilde{b}=\left(b^{1}, b^{2}, b^{3}\right)$ and $\tilde{a}=\left(a^{1}, a^{2}, a^{3}\right)$, the following operation is satisfied:

(1) Addition

$$
\tilde{b}+\tilde{a}=\left(b^{1}+a^{1}, b^{2}+a^{2}, b^{3}+a^{3}\right)
$$


(2) Scalar Multiplication

$$
k * \tilde{b}=\left(k * b^{1}+k * b^{2}+k * b^{3}\right)
$$

Where, $\mathrm{k}$ is a real number.

(3) Multiplication

$$
\tilde{b} * \tilde{a}=\left(b^{1} * a^{1}, b^{2} * a^{2}, b^{3} * a^{3}\right)
$$

(4) Division

$$
\tilde{b} / \tilde{a}=\left(b^{1} / a^{3}, b^{2} / a^{2}, b^{3} / a^{1}\right)
$$

\section{Triangular fuzzy number normalization for performance evaluation indices}

During the performance evaluation of college students' ideological and political education, the diversified indices often have different dimensions. To make effective measurement, these indices should be normalized

Assuming that the number of performance evaluation objects is $M$, the number of indices of the evaluation is $N$, and the triangular fuzzy value of the evaluation object $i$ with respect to the index $j$ is $\tilde{v}_{i j}\left(v_{i j}^{1}, v_{i j}^{2}, v_{i j}^{3}\right)$. If the index is a benefit-oriented decision-making index, the normalized triangular fuzzy value is $\tilde{r}_{i j}\left(r_{i j}^{1}, r_{i j}^{2}, r_{i j}^{3}\right)$ i.e.:

$$
\tilde{r}_{i j}\left(r_{i j}^{1}, r_{i j}^{2}, r_{i j}^{3}\right)=\left(\frac{v_{i j}^{1}}{\max _{1 \leq i \leq M}\left(v_{i j}^{3}\right)}, \frac{v_{i j}^{2}}{\max _{1 \leq i \leq M}\left(v_{i j}^{3}\right)}, \frac{v_{i j}^{3}}{\max _{1 \leq i \leq M}\left(v_{i j}^{3}\right)}\right)
$$

If the index is a cost-oriented decision-making index, the normalized triangular fuzzy value is $\tilde{r}_{i j}\left(r_{i j}^{1}, r_{i j}^{2}, r_{i j}^{3}\right)$ i.e.:

$$
\tilde{r}_{i j}\left(r_{i j}^{1}, r_{i j}^{2}, r_{i j}^{3}\right)=\left(\frac{\min _{1 \leq i \leq M}\left(v_{i j}^{1}\right)}{v_{i j}^{3}}, \frac{\min _{1 \leq i \leq M}\left(v_{i j}^{1}\right)}{v_{i j}^{2}}, \frac{\min _{1 \leq i \leq M}\left(v_{i j}^{1}\right)}{v_{i j}^{1}}\right)
$$

The above normalization ensures that the triangular fuzzy number $\tilde{r}_{i j}\left(r_{i j}^{1}, r_{i j}^{2}, r_{i j}^{3}\right)$ satisfies the requirement of $0 \leq r_{i j}^{1} \leq r_{i j}^{2} \leq r_{i j}^{3} \leq 1$, that is, all triangular fuzzy numbers have a uniform scale, which guarantees the reliability of the analysis results.

\section{Similarity of triangular fuzzy numbers}

After the data statistics and analysis, the author acquires the triangular fuzzy value of different indices. With these indices, the author constructs the initial triangular fuzzy number matrix $V$ for the performance evaluation of college students' ideological and political education. 


$$
\mathbf{V}=\left[\begin{array}{ccccc}
\tilde{v}_{11} & \ldots & \tilde{v}_{1 j} & \ldots & \tilde{v}_{1 N} \\
\vdots & \vdots & \vdots & \vdots & \vdots \\
\tilde{v}_{i 1} & \cdots & \tilde{v}_{i j} & \ldots & \tilde{v}_{i N} \\
\vdots & \vdots & \vdots & \vdots & \vdots \\
\tilde{v}_{M 1} & \cdots & \tilde{v}_{M j} & \cdots & \tilde{v}_{M N}
\end{array}\right]
$$

After normalization, the normalized triangular fuzzy number matrix $\mathrm{R}$ is obtained:

$$
\mathbf{R}=\left[\begin{array}{ccccc}
\tilde{r}_{11} & \ldots & \tilde{r}_{1 j} & \ldots & \tilde{r}_{1 N} \\
\vdots & \vdots & \vdots & \vdots & \vdots \\
\tilde{r}_{i 1} & \ldots & \tilde{r}_{i j} & \ldots & \tilde{r}_{i N} \\
\vdots & \vdots & \vdots & \vdots & \vdots \\
\tilde{r}_{M 1} & \cdots & \tilde{r}_{M j} & \ldots & \tilde{r}_{M N}
\end{array}\right]
$$

The author selects the maximum value on each row of the triangular fuzzy number matrix R, thus getting the optimal triangular fuzzy values of different indices. The optimal triangular fuzzy numbers of the indices are denoted as $\tilde{u}_{i j}\left(u_{i j}^{1}, u_{i j}^{2}, u_{i j}^{3}\right)$, i.e.

$$
\tilde{u}_{i j}\left(u_{i j}^{1}, u_{i j}^{2}, u_{i j}^{3}\right)=\left(\max _{1 \leq i \leq M}\left(r_{i j}^{1}\right), \max _{1 \leq i \leq M}\left(r_{i j}^{2}\right), \max _{1 \leq i \leq M}\left(r_{i j}^{3}\right)\right)
$$

Hence, the similarity between the triangular fuzzy value of the evaluation object $\mathrm{i}$ with respect to the index $\mathrm{j}$ and the optimal triangular fuzzy number $\tilde{\mathrm{u}}_{\mathrm{ij}}\left(\mathrm{u}_{\mathrm{ij}}^{1}, \mathrm{u}_{\mathrm{ij}}^{2}, \mathrm{u}_{\mathrm{ij}}^{3}\right)$ can be expressed as $\lambda_{\mathrm{ij}}^{1}$ :

$$
\lambda_{i j}^{1}=\frac{r_{i j}^{1} * u_{i j}^{1}+r_{i j}^{2} * u_{i j}^{2}+r_{i j}^{3} * u_{i j}^{3}}{\max \left[\left(r_{i j}^{1}\right)^{2}+\left(r_{i j}^{2}\right)^{2}+\left(r_{i j}^{3}\right)^{2},\left(u_{i j}^{1}\right)^{2}+\left(u_{i j}^{2}\right)^{2}+\left(u_{i j}^{3}\right)^{2}\right]}
$$

Or, the similarity between the triangular fuzzy value of the evaluation object $i$ with respect to the index $j$ and the optimal triangular fuzzy number $\tilde{u}_{i j}\left(u_{i j}^{1}, u_{i j}^{2}, u_{i j}^{3}\right)$ can be expressed as $\lambda_{i j}^{2}$ :

$$
\lambda_{i j}^{2}=\frac{\min \left[\left(r_{i j}^{1}\right)^{2}+\left(r_{i j}^{2}\right)^{2}+\left(r_{i j}^{3}\right)^{2},\left(u_{i j}^{1}\right)^{2}+\left(u_{i j}^{2}\right)^{2}+\left(u_{i j}^{3}\right)^{2}\right]}{r_{i j}^{1} * u_{i j}^{1}+r_{i j}^{2} * u_{i j}^{2}+r_{i j}^{3} * u_{i j}^{3}}
$$

In application, the analyzer can either choose to use one of expression, or obtain a similarity $\lambda_{\mathrm{ij}}$ through comprehensive treatment of the two expressions, i.e.:

$$
\lambda_{i j}=\lambda_{i j}^{1}+(1-\xi) * \lambda_{i j}^{2}
$$

Where, $0 \leq \xi \leq 1$.

\section{Performance evaluation model of college students' ideological and poitical education}

From above, the author obtains $\gamma_{i}$, the similarity between the triangular fuzzy value of each evaluation object with respect to a certain index and the optimal triangular fuzzy number $\tilde{u}_{i j}\left(u_{i j}^{1}, u_{i j}^{2}, u_{i j}^{3}\right)$ :

$$
\gamma_{i}=\sum_{j=1}^{N}\left(w_{j} * \lambda_{i j}\right)
$$


Thereby, the author establishes the performance evaluation model of college students' ideological and political education, i.e.;

$$
\gamma_{\max }=\max _{1 \leq i \leq M}\left(\gamma_{i}=\sum_{j=1}^{N}\left(w_{j} * \lambda_{i j}\right)\right)=\gamma_{k}
$$

$\mathrm{k}$ stands for the object with the optimal performance.

\section{Steps of model implementation}

To sum up, the model implementation steps can be expressed as follows:

(1) In light of the actual situation, select the reasonable evaluation indices targeted at the needs of the performance evaluation of college students' ideological and political education.

(2) Obtain the triangular fuzzy value of each performance evaluation object with respect to the indices, forming the initial triangular fuzzy number matrix.

(3) Normalize the initial data according to the type of the index and the triangular fuzzy number normalization model, acquiring the normalized triangular fuzzy number matrix $R$.

(4) Obtain the optimal triangular fuzzy numbers of the indices based on triangular fuzzy number matrix $R$.

(5) According to the calculation model for the similarity between triangular fuzzy numbers, obtain the similarity between the triangular fuzzy value of each evaluation object with respect to a certain index and the optimal triangular fuzzy number.

(6) Select the appropriate weight acquisition method to determine the weight of different indices.

(7) Calculate the comprehensive similarity between different performance evaluation objects with respect to a certain index and the optimal triangular fuzzy number.

(8) Based on the performance evaluation model of university students' ideological and political education, analyze the comprehensive similarity and obtain the evaluation object with the best performance.

\section{Conclusion and Prospect}

This paper has two innovations during the preliminary discussion and the analysis of the performance evaluation of college students' ideological and political education. this main innovation spot manifests in two aspects.

(1) From a more scientific, holistic, comprehensive and objective perspective, the author gives a new performance evaluation index system of college students' ideological and political education, and carries out comprehensive analysis of the theoretical soundness, practical feasibility and integration capacity of ideological and political education. 
(2) To ensure the practicality and reliability of the evaluation results, the author provides an improved fuzzy evaluation model of college students' ideological and political education, and conducts quantitative analysis of performance evaluation indices of various forms and types.

With the rapid social development, the existing evaluation index systems and models of ideological and political evaluation may more or less have limitations. Therefore, the systems and models ought to be improved and developed with the time. Keeping abreast with the times is the only way to effectively promote the capacity and level of ideological and political education.

\section{References}

Ban, A. I., \& Coroianu, L. (2015). Existence, uniqueness, calculus and properties of triangular approximations of fuzzy numbers under a general condition. International Journal of Approximate Reasoning, 62, 1-26. http://dx.doi.org/10.1016/j.ijar.2015.05.004

Chandra, S., \& Aggarwal, A. (2015). On solving matrix games with pay-offs of triangular fuzzy numbers: Certain observations and generalizations. European Journal of Operational Research, 246(2), 575-581. http://dx.doi.org/10.1016/j.ejor.2015.05.011

Chatterjee, A., Mukherjee, S., \& Kar, S. (2014). Poverty level of households: A multidimensional approach based on fuzzy mathematics. Information and Engineering, 6(4), 463-487. http://dx.doi.org/10.1016/j.fiae.2015.01.005

Guo, J. S., \& Li, S. F. (2008). Establishment of the undergraduates' ideological and political education appraisement system through ecological point of view. Journal of Jinling Institute of Technology, 22(3), 8184.

Li, S., \& Ou, A. X. (2015). The effectiveness students' ideological evaluation model of university and political education based on the fuzzy mathematics theory. Mathematics in Practice and Theory, 45(13), 299-306.

Li, W. D. (2008). On setting effectiveness evaluation index system of the ideological and political education of college students. Journal of Maoming University, 18(5), 10-13, 56.

Li, Z. J. (2012). Analyses on the nature of ideological and political education. Journal of Northeast Normal University (Philosophy and Social Sciences), (5), 227-231.

Liao, Y., \& Chen, H. Q. (2015). Modelling of triangular fuzzy number in multi-attribute decision-making. Computer Engineering and Applications, 51(11), 206-211.

Long, R. Y. (2013). The content and indicator system construction of postgraduate student's ideological and political theory course teaching evaluation. Chongqing Higher Education Research, 1(6), 96-100.

Molinari, F. (2016). A new criterion of choice between generalized triangular fuzzy numbers. Fuzzy Sets and Systems, 296(1), 51-69.

She, S. H. (2014). The problems and trends of the development of ideological and political education. Studies in Ideological Education, (1), 11-14.

Shidpour, H., Da Cunha, C., \& Bernard, A. (2016). Group multi-criteria design concept evaluation using combined rough set theory and fuzzy set theory. Expert Systems with Applications, 64, 633-644. http://dx.doi.org/10.1016/j.eswa.2016.08.022 
Wu, Q. T., \& Zhang, X. Q. (2014). A review of the research on the connotation and orientation of ideological and political education. Studies in Ideological Education, (5), 3-15.

Yang, X., \& Wang, H. Y. (2010). Evaluation system of ideological and political education performance based on analytic network process. Journal of Kurming University of Science and Technology, 10(1), 403-413.

Zhang, H. X., \& Liu, Y. Z. (2011). On the evaluation principles of college ideological and political education effectiveness in the background of cultural pluralism. Journal of China University of Petroleum (Edition of Social Sciences), 27(1), 103-108.

Zhang, Y. T. (2011). Approach innovation of college ideological and political education under the background of campus new media. Journal of China University of Petroleum (Edition of Social Sciences), 27(5), 103108. 